\title{
L'an zéro du monde contemporain à la Biennale de Venise: de Aperto à une Strada Novissima
}

\section{Kornelia Imesch}

\section{(2) OpenEdition}

1 Journals

Édition électronique

URL : http://journals.openedition.org/edl/2434

DOI : $10.4000 /$ edl.2434

ISSN : 2296-5084

\section{Éditeur}

Université de Lausanne

\section{Édition imprimée}

Date de publication : 15 mars 2020

Pagination : 193-196

ISBN : 978-2-940331-73-4

ISSN : 0014-2026

\section{Référence électronique}

Kornelia Imesch, «L'an zéro du monde contemporain à la Biennale de Venise: de Aperto à une Strada Novissima », Études de lettres [En ligne], 312 | 2020, mis en ligne le 24 mars 2020, consulté le 17 septembre 2020. URL : http://journals.openedition.org/edl/2434 ; DOI : https://doi.org/10.4000/edl. 2434

\section{(c) Études de lettres}




\section{L'AN ZÉRO DU MONDE CONTEMPORAIN À LA BIENNALE DE VENISE: DE APERTO À UNE STRADA NOVISSIMA}

La question de l'année 1980, envisagée comme "an zéro du monde contemporain", se cristallise dans le domaine artistique lors de la Biennale de Venise, et plus précisément à travers deux expositions qui ont écrit cette année-là l'histoire de la discipline, et a fortiori l'histoire de la Biennale elle-même: Aperto, organisée par le curateur suisse Harald Szeemann, et La Presenza del Passato (La Présence du Passé), avec sa partie principale, La Strada Novissima, dirigée par l'architecte italien Paolo Portoghesi.

La première exposition assurait à des artistes très jeunes et pas encore confirmés leur entrée à la Biennale de Venise. Aperto officialisait et institutionnalisait ainsi l'(ultra-)contemporain au sein de cette digne "mère" des Biennales, désormais devenue à cette époque de plus en plus âgée et désuète. Lautre exposition, qui misait également sur le présent et sur l'actualité, marquait l'entrée officielle de l'architecture comme domaine à part entière de la Biennale à Venise (après des premières tentatives sans impacts majeurs dans les années 1970). La Presenza del Passato était donc la première Biennale d'architecture organisée à Venise, introduite thématiquement une année auparavant par une installation flottante d'Aldo Rossi, Teatro del Mondo (1979-1980). Cette première Biennale d'architecture complète alors la série des différentes Biennales - d'art visuel, de cinéma, de musique et de théâtre - qui, sur le modèle de la première Biennale d'art plastique de la fin du XIX ${ }^{\mathrm{e}}$ siècle, se sont installées à Venise dans les années 1930 sous le régime fasciste de Mussolini, qui reconnaissait l'utilité idéologique et économique de cet instrument 
culturel (la Biennale) pour Venise et plus généralement pour la société italienne de l'époque.

Fondée en 1895, la Biennale d'art visuel ouvrait un nouveau chapitre pour la ville sur la mer, considérée alors comme une ville «à l'agonie». Elle assura et garantit d'ailleurs toujours à Venise, sa survie culturelle et économique. Initiée par la municipalité vénitienne, cette grande exposition d'art international s'approprie le modèle des expositions universelles qui, depuis 1851, permettent dans différents secteurs sociétaux une sorte de globalisation des marchés et des cultures avant la lettre.

Officiellement inaugurée pour célébrer les vingt-cinq ans de mariage du roi Umberto ${ }^{\text {er }}$ et de Marguerite de Savoie, cette première grande exposition d'art international vénitienne est en réalité créée dans un but d'économie créative et de city branding. En effet, le but premier de l'initiative était de ranimer Venise comme centre artistique et de réactiver par ce biais le tourisme culturel. Il s'agit là d'un phénomène bien connu et d'un instrument stratégique systématiquement appliqué surtout à partir des années 1980 et 1990, à une époque de renouveau culturel global que l'on peut appeler "postmodernisme", soit en substance une ère caractérisée par un double mouvement d'économisation de l'esthétique et d'esthétisation de l'économie.

Mais revenons aux deux expositions nommées évoquées ci-dessus. Leurs enjeux étaient, on l'a évoqué, multiples. Tout d'abord, elles étaient les deux (pour différentes raisons) localisées extra muros, hors des Giardini, lieu traditionnel des différents pavillons nationaux. L'exposition Aperto de Szeemann eut lieu dans les Magazzini del Sale sur les Zattere, tandis que l'exposition La Strada Novissima de Portoghesi prit place dans les Corderie de l'Arsenale (l'ancien chantier naval), donc dans le vieux centre économique et industriel de la ville. Ce qui peut être lu à première vue comme une marginalisation dévaluant les deux évènements, est au contraire une forme d'anticipation du potentiel prospectif de ces expositions et de ce qu'elles représentent: les deux expositions initient alors par leur localisation, l'appropriation de la ville entière par la Biennale.

Les deux évènements marquent donc le début du développement qui caractérise aujourd'hui la Biennale: d'une part, sa prolifération sur l'Arsenale comme chantier de la culture et des arts, de l'autre, son extension sur toute la ville par des "eventi collaterali» (événements associés). Autrement dit, Venise comme ville est aujourd'hui elle-même non pas seulement un immense musée, mais aussi une immense Biennale, un 
grand chantier expérimental de culture et d'arts d'où s'est répandu le phénomène actuel d'une véritable biennalisation des mondes de l'art en tant que signe et effet de la globalisation des scènes artistiques après 1989. Aperto de Szeemann, thème qu'il reprendra comme dAPERTtutto pour la Biennale de 1999, signale donc l'ouverture de la scène artistique, et plus largement l'ouverture de la Biennale à la contemporanéité, l'art de l'an zéro, mais également l'ouverture topographique de cette dernière à la ville entière.

La Strada Novissima, partie principale de l'exposition La Presenza del Passato de Portoghesi, inaugure quant à elle l'Arsenale et ses Corderie comme lieu d'exposition, et anticipe par là même un modèle récurrent de l'économie créative, culturelle et urbaine de nos jours: la transformation d'un chantier industriel désaffecté en nouveau chantier culturel et artistique prospère. Le titre de l'exposition, La Presenza del Passato, est particulièrement significatif dans le contexte des vives et polémiques discussions théoriques italiennes de cette époque, discussions notamment saisissables dans des revues et magazines d'architecture comme Controspazio ou Contropiano, ou dans un traité comme celui d'Aldo Rossi, L'Architettura della città (1966). Il s'agit là d'un texte fondateur d'un nouveau débat architectural et urbain, dont les thèses principales décrivant un processus de transformation urbaine tenant compte du passé dans le présent, s’adaptent parfaitement à une ville comme Venise qui vit précisément à l'aune de ce processus de continuation du passé dans le présent. C'est bien cette dynamique complexe qui est en définitive au cœur de l'exposition La Strada Novissima de Portoghesi, à l'image de ses vingt façades spectaculaires et théâtrales réalisées par vingt architectes internationaux.

Par ailleurs, les deux expositions introduisent une tonalité nouvelle dans cette digne institution qu'est la Biennale de Venise: une tonalité et un habitus jeune, bruyant, polémique, beau, mais impertinent et fou, coloré, spectaculaire, théâtrale et interactif, ironique et fantastique. Bref, les deux expositions s'inscrivent chacune à leur manière dans le courant postmoderniste et mettent en pratique le cri de ralliement de Leslie A. Fiedler: "Cross the Border - Close the Gap" (1969/1972). La Strada Novissima pour une nouvelle présence (éternelle) du passé constitue en effet la toute première exposition du postmodernisme architectural en Europe et ouvre ainsi le Vieux Continent à ce nouveau courant et à sa logique du «Less is a bore» formulée par Robert Venturi quelques années plus tôt. 
1980 comme l'an zéro du contemporain, dévoile alors à travers ces deux expositions la vie et la signification implicite de Venise comme musée, comme chantier artistique, mais aussi comme parc d'attractions, comme un autre "Las Vegas» européen. Finalement, les deux expositions rappellent chacune à leur manière l'importance du geste institutionnel de l'«exposition" pour la réception de nouveaux discours et l'élaboration d'une écriture critique de l'histoire de l'art ultra-contemporain.

Kornelia ImEsch

Section d'histoire de l'art, Faculté des lettres, Université de Lausanne

\section{BIBLIOGRAPHIE}

ARCHITECTURE 1980. The Presence of the Past. Venice Biennale, New York, Rizzoli, 1980.

Di Martino, Enzo, The History of Venice Biennale 1895-2005. Visual Arts - Architecture - Cinema - Dance - Music - Theatre, Venezia, Papiro Arte, 2005.

FIedler, Leslie A., «Überquert die Grenze, schliesst den Graben! Über die Postmoderne", in Wege aus der Moderne. Schlüsseltexte der Postmoderne-Diskussion, hrsg. von Wolfgang Welsch, Weinheim, Acta humaniora, 1988, p. 57-74.

Fleck, Robert, Die Biennale von Venedig. Eine Geschichte des 20. Jahrhunderts, Hamburg, Philo Fine Arts, 2009.

Levy, Aaron, Menking, William, Architecture of Display: On the History of the Venice Biennale of Architecture, London, Architectural Association AA Publications, 2010.

Ricci, Clarissa (dir.), Starting from Venice. Studies on the Biennale, Milan, Université IUAV de Venise, 2010.

Rossi, Aldo, L'architettura della città (1966), Torino, CittàStudi, 2006.

Szacka, Léa-Catherine, Exhibiting the Postmodern. The 1980 Venice Architecture Biennale, Venezia, Marsilio, 2016.

SzEemann, Harald (dir.), dAPERTtutto = Aperto over all = Aperto par tout = Aperto überall (La Biennale di Venezia - 48a Esposizione internazionale d'arte), Venezia, Marsilio, 1999. 